\title{
Identifying, ordering and defining senses
}

\author{
Robert Lew
}

\section{Sense(s) in language versus senses in the dictionary}

Linguists and philosophers of language have often talked of sense as a mass noun, typically in opposition to reference, where sense would refer to conceptual meaning, contrasted with a piece of the world that a linguistic expression refers to.

In a dictionary, however, senses are something distinctly different. They are basic units of entry organization: the most distinct component parts of the dictionary article. Piotrowski (1994: 21) defines a sense in lexicography as 'one of the main divisions of the entry, usually marked typographically by consecutive letters or numbers'. Indeed, senses are often explicitly numbered in sequence, less commonly prefixed by letters, or punctuated in a typographically more subtle manner, such as by semicolons. Occasionally, special symbols are used to effect a visual separation of senses, such as a diamond $\bullet$, centred dot $\bullet$, triangle $\boldsymbol{\nabla}$, or square $\mathbf{m}$.

Dictionary senses may be run on (= continued on the same line), but they may also be given each on its own line. A one-sense-per-line presentation is generally believed to be easier to navigate, but it comes at the cost of using up more space. For this reason, this option is particularly common in on-screen presentation of electronic dictionaries and whenever user friendliness takes precedence over space considerations, such as in dictionaries directed at language learners or children. To make a general point, entry organization in a dictionary serves the purpose of enabling users to locate, and then make good sense of the lexicographic data included in the entry. In most dictionary projects, the aim is to create efficient and effective tools, assisting the user in whatever lexicographically relevant queries, problems and doubts they may have, and good entry organization improves the efficiency of the dictionary as a tool.

Dictionary users (including many linguists!) tend to conflate these two rather distinct meanings of sense, assuming without much reflection that when they look up a word in a dictionary, the senses present in the entry mirror what goes on in the language. In most cases, the correspondence is far from perfect, though generally speaking it tends to be closer in monolingual than in bilingual dictionaries. Also, such an approximation is less of a distortion in academic (or 'scholarly') dictionaries, whose general aim may be to present a reasonably faithful portrait of a language. However, the fact that such dictionaries often include a diachronic dimension reinforces the point that lexicographic sense division cannot be expected so readily to mirror linguistic reality, however the latter is to be understood.

Further evidence of the relative autonomy of the lexicographic sense from the linguistic notion by the same name comes from the practice of the elevation of multi-word expressions to sense status in some dictionaries. Multi-words are not infrequently presented on a par with the more 'traditional' dictionary senses. For example, Longman Dictionary of Contemporary English (free online version) enters eight senses of TRAIN as a noun. Interspersed in between the more conventional senses are four multi-word items: senses four and five respectively are the milti-words bring something in its train and set something in train. Clearly, these two expressions instantiate quite similar semantic values of the lemma TRAIN, and yet they are listed

Preprint version of:

Lew, Robert. 2013. 'Identifying, Ordering and Defining Senses' In Jackson, Howard (ed.), The Bloomsbury Companion to Lexicography. London: Bloomsbury Publishing.

http://www.bloomsbury.com/uk/bloomsbury-companion-to-lexicography-9781441145970/ 
as separate senses. Conversely, there are also many dictionaries which lump all multi-words under a single dictionary sense. This broad variation in lexicographic practice strengthens the point that the lexicographic sense may bear, at best, a tenuous relationship to linguistic notions. It is clear that discrete senses exist in dictionaries, but do they exist in language as well?

\subsection{Are senses discrete entities?}

As explained above, the question of atomicity of senses can apply to both the lexical units of a language and the structural elements of a dictionary. Linguists do not all agree on the issue of atomicity of senses. Some of those that do see meanings as atomic like to embark on the ambitious quest for the boundary between polysemy and vagueness. The opposite view is well represented by, for example, Patrick Hanks (2000: 211), who maintains that words only carry meaning potentials which are rather vague, and do not take on their full shape outside of their context (which includes, but is not exhausted by, co-text). There is nothing wrong with such vagueness, and it may actually foster language creativity, allowing speakers to express new ideas with existing words. Patrick Hanks and John Sinclair have also argued against a strict separation of form and meaning, showing from corpus evidence that the two tend to go hand in hand: like meanings tend to be expressed through like structures. But, again, 'tend to' is the operative word, as language is nowhere near as ordered as many linguists would like it to be. Another pertinent observation that lexicographers and linguists owe to Sinclair is dispelling the myth of orthographic words as principal carriers (or containers) of meaning: units of meaning should not be seen as being co-extensive with orthographic spaces (the idiom principle).

Paradoxically, the very fact that so many linguists seem to feel comfortable with the idea of atomic senses in language may well be a reflection of linguists' practical, pre-theoretical experience with dictionaries (Nowakowski 1990: 10; Burkhanov 1997: 70). It is not at all unlikely that repeated exposure to structured dictionary entries by linguists-to-be in the role of ordinary dictionary users may have shaped their future thinking on how language itself might be structured. In a similar vein, Hanks (2000: 205) notes that ' $[t]$ he numbered lists of definitions found in dictionaries have helped to create a false picture of what really happens when language is used'.

In this context, it is appropriate to reflect on what the 'identification of senses' in the chapter title might really refer to. Who does the identifying and what is the thing that is being identified? One answer that can be given with some confidence is that dictionary users identify senses in the dictionary which they happen to be consulting: they look for the structural segments of entries which best fit the problem at hand which has prompted them to consult a dictionary in the first place. These senses have been put in the dictionary by the lexicographer. But has the lexicographer actually ever identified these exact senses in the language? This is a tough question and the answer can at best be a qualified yes, with the degree to which it may be true depending on the type of the vocabulary item. Some words appear to have meanings which are relatively fixed and do not yield that much to contextual coercion (such words are sometimes termed autosemantic). But there are other words which of themselves tend to be rather vague and pick up a significant portion of their meaning from the context (relatively synsemantic words). Very common words can be semantically impoverished, such as, in English, have in have a go.

Today, much lexicographic work is done by examining massive corpus evidence, but, as any novice lexicographer is soon bound to discover, it is notoriously difficult to compartmen- 
talize corpus citations into discrete senses. Having access to greater volumes of data usually makes the problem even harder: for commoner words, lexicographers have to wrestle with hundreds of citations and try to group them into manageable clusters of meaning. As a result, as pointed out by van der Meer (2004: 807), 'one of the hardest problems torturing practising lexicographers has always been the question of how to describe the meaning of so-called polysemous words'. Atkins and Rundell (2008: 264) concur when they state that 'there is little agreement about what word senses are (or even whether they exist). Lexicographers are therefore in the position of having to describe something whose nature is not at all clear'. Consequently, Kilgarriff (Kilgarriff 1997) in a paper with a telling title ('I don't believe in word senses') rejects the word sense-being an ill-defined entity-as the basic unit. Instead, dictionary word senses are the result of clustering attested uses appearing as concordance lines. So, although there may be no discrete senses in language, they do exist as artefacts in a dictionary.

\section{Specifying senses in monolingual dictionaries}

The modern lexicographer is often confronted with hundreds of citations and faces the intimidating task of having to arrange them neatly into portions appetizing enough to be appreciated by future dictionary users. Working with large corpora is a humbling experience for linguists, and the job of arranging a multitude of corpus citations into neat, discrete senses, is far less obvious than many would believe. In fact, two opposing strategies have been identified at this stage of dictionary compilation, known as lumping and splitting. The first strategy aims to minimize the number of senses so that they each cover as much semantic ground as possible. In contrast, those who follow the second strategy ('the splitters') will tend to generate a rather larger number of finely distinguished senses.

As Hanks (2000: 208) observes, exposure to ever-growing corpora naturally entices lexicographers into adding yet further definitions to the dictionary. This happens in part because it does seem easier than reflecting on whether the definitions already in place can be modified to accommodate the newly encountered usage, but also because having a lot of 'meanings' is often seen as a desirable feature from a marketing point of view, so as to boost the number of 'references' that can later be bandied about in promotional materials.

But even in corpus citation lines, meanings do not lie there exposed and ready to be picked up or 'discovered'. Rather, corpus lines provide evidence of 'traces of meaning events' (Hanks 2000: 211).

That senses in dictionaries do not have as much grounding in linguistic reality as is often naively held, can be readily ascertained by examining closely analogous entries in different dictionaries. To work through a concrete example, let us take the noun MIND. In the online version of the Longman Dictionary of Contemporary English, this lemma receives three senses, if we ignore the metonymically derived sense 'intelligent person' and all the numerous multi-word expressions:

1. your thoughts or your ability to think, feel, and imagine things

2. used to talk about the way that someone thinks and the type of thoughts they have

3. your intelligence and ability to think, rather than your emotions

In contrast, a close competitor, Oxford Advanced Learner's Dictionary, also available online, gives four rather different senses: 
1. the part of a person that makes them able to be aware of things, to think and to feel

2. your ability to think and reason; your intelligence; the particular way that somebody thinks

3. your thoughts, interest, etc

4. your ability to remember things

At the same time, the DANTE lexical database gives no fewer than eight senses covering roughly the same semantic space. Surely, the best professional lexicographers cannot be describing the same reality? The undeniable observation that the more voluminous ('comprehensive') a dictionary, the greater the number of senses it will tend to have for a typical common word (and not just because larger dictionaries address areas of meanings excluded from smaller ones!), testifies to the fact that senses in the dictionary are only objective with respect to the entry structure of this dictionary. They should not be seen as an objective representation of language in any dimension. At the very most, they are attempts at such a representation, but filtered through the practical realities of the particular lexicographic project, dictated by the foreseen target users and uses, and constrained by the available financial, human, and technical resources.

Rundell (1999: 40) makes the point clearly when he observes:

(as lexicographers have always known), the notion that a given word has five or ten or twenty 'senses' is simply a useful working convention without any objective truth-value (...) What dictionary-makers attempt to do is to segment this continuum of meaning in ways that will provide maximum benefit to the target user.

It is not irrelevant to observe at this point that dictionary senses are not necessarily always designed to represent separate 'meanings' of the strict semantic kind. Instead, separate sense status may be accorded to distinct uses of the word. For example, verb entries may be structured by the syntactic patterns of use in which they are observed.

\section{Senses in bilingual dictionaries}

\subsection{Meaning structure versus equivalence structure}

In bilingual dictionaries, the issue of sense division is more complex, as it involves, not one, but two lexical systems. In organizing the entry into senses, lexicographers may thus be guided by interlingual equivalence relations. This provides an extra criterion, and a relatively objective one at that, especially if, in the near future, suitable parallel corpora become more widely available as a source of evidence on textual equivalence between lexical items in two (or more) languages (an idea which goes back to Hartmann 1985).

The issue was taken up (among others) by Manley, Jacobsen and Petersen (1988), who use the term meaning structure to refer to a type of sense organization which relies on the source language solely, and equivalence structure to one based on the equivalence relations with the target language. They assert that 'meaning structure is a relic from the monolingual dictionary and ... the more we can approach equivalence structure the closer we will get to the ideal form of the bilingual dictionary' (1988: 296). Most authors writing on the issue concur that senses need to reflect such equivalence relations, even if the description of the source language gets 'subtly distorted' (Atkins 1996: 523) in the process. 
There are actually two opposing aspects of equivalence structure: (1) sense distinctions in the source language may be redundant and undergo elimination; and (2) it may be advisable to introduce extra distinctions so as to provide a tighter match between the lexical items in the two languages.

To illustrate the first scenario, quite a few senses of the English high which tend to be distinguished in monolingual dictionaries translate into German as hoch. All these senses of English could then be conflated in an English-to-German dictionary, thus making the entry presentation more economical and, arguably, easier to navigate and use. But there are doubts, such as what to do when a given sense in L1 has another important translation in L2. Decisions like these are usually best made on a per-case basis, depending on the particular constellation of equivalents and also on what functions the dictionary is envisaged to perform.

Conversely, what appears to be a single sense in a source-language item may require splitting according to substantive distinctions in the target language. For example, the English noun drift in the sense 'deviation from course' has different equivalents in Russian depending on whether it refers to an aircraft (дрейф) or a vessel (снос). Therefore, the option of separating the two meanings or uses out as either senses or subsenses might at least be considered, if not always acted upon. Of course, one could argue in such cases that we are dealing with the same 'sense', merely providing a choice of equivalents that are restricted in their use. But this just begs the question of what a 'sense' is; if we see it, as I believe we should in this context, as a lexicographic construct rather than a linguistic one, then it is certainly something that can be split.

Even when dictionary editors aim in principle for equivalence structure, practical considerations may prevail and skew the structure in the direction of that found in a monolingual dictionary. This can happen because a monolingual dictionary of a language is not infrequently a starting point in the compilation of a bilingual dictionary with this language as the dictionary's SL. Alternatively, lexicographers may start with a universal framework of that language created to be used as a skeleton in bilingual projects. It is only natural that this SLbased structure will tend to impress itself on the final product, even if this is not the intention of the lexicographer.

Meaning structure is overtly aimed for in dictionaries following what Jarošová (2000: 18) calls the explanatory principle. This echoes Lev Shcherba's idea of the explanatory dictionary originally expressed in the 1940's (Shcherba 1995: is the English-language version). Meaning structure is also sanctioned in most semi-bilingualized dictionaries, where lexicographers are often discouraged, if not downright prohibited, from manipulating the sense divisions inherited from the monolingual model dictionary. At times, this frustrates the bilingual lexicographer. To use an example from my own experience when working on a Polish adaptation of a major monolingual learner's dictionary, I had to contend with the basic sense of the English verb POUR being defined as 'to make a liquid flow from or into a container'. This sense was supposed to subsume a similar action on powdery substances such as sugar. The problem is that Polish requires completely different verbs in the two cases, but as splitting senses was not an option, I had to settle for an awkward side-by-side presentation of two totally unrelated (from the point of view of the Polish user) equivalents.

All in all, except in artificial cases such as the last one described, it should by now be apparent that the sense structure of most existing bilingual dictionaries is usually a compromise between the analysis of the source language and the constellation of the TL equivalents of the source item. It can be argued that a bilingual dictionary with a dominant text production func- 
tion might benefit from a sense structure closer to that of a monolingual dictionary of the source language. Here, the typical user of such an entry has limited knowledge of the target language and may not recognize at least some of the equivalents given. If so, they need guidance in the source language (either their native language or at least one they speak better than the TL), and such guidance more naturally mimics the distinctions typical of a monolingual dictionary. Still, if several senses share the same equivalent, there is no compelling reason not to combine them, thus saving a considerable amount of space and improving the visibility of the remaining senses with perhaps more unusual equivalents.

\section{Ordering senses}

\subsection{Ordering senses in monolingual dictionaries}

The major approaches to sense ordering should be seen as guidelines rather than hard-andfast rules, as excessively orthodox adherence to any one such principle is likely to lead to undesirable outcomes for some entries. A notorious example is the entry SUMMIT in the first edition of COBUILD (Sinclair and Hanks 1987), where sense ordering according to corpus frequency compelled the lexicographers to list the 'political meeting' sense first, before the 'top of the mountain' sense. This example underscores the fact that, above all, common sense should prevail over any strict application of principles. As lexicographers discover over and over again in the course of their work, the lexicon of a natural language is not regular enough for an across-the-board treatment to work seamlessly for all items. Rather, we should always remain open to individual solutions, and not hesitate to depart from the general principle whenever the peculiarity of a lexical item justifies this. Having said that, consistency is in general seen as a virtue in dictionaries, so guiding principles are needed. The most popular principles of relevance in guiding sense ordering are: chronology, frequency, markedness, and logic.

\subsubsection{Chronology}

In chronological ordering, also known as historical, senses are arranged from the earliest attested to the most recent. As one would expect, the principle is most relevant for historical and diachronic dictionaries. However, there also exist general dictionaries using this arrangement. For example, the American dictionary publisher Merriam Webster's Incorporated has insisted on the application of the historical principle in its range of general dictionaries, including the popular Merriam-Webster's Collegiate Dictionary. This dictionary was found inferior for US college students compared with other dictionaries aimed at college students or advanced learners of English (McCreary and Amacker 2006; McCreary 2008; McCreary 2010). In a large measure, the disappointing performance of the Merriam-Webster dictionary was ascribed to its policy (Mish 2004: 20a) of placing first historically oldest senses which are no longer current. In view of the evidence that dictionary users all too often do not read dictionary entries beyond the first sense (Tono 1984; Lew 2004), placing a non-contemporary meaning in this privileged position is counterproductive for most typical uses of the dictionary. McCreary (2008) suggests that this policy should be reversed by placing archaic senses towards the end of the entry.

\subsubsection{Markedness}

Relegating archaic senses to the final sections of an entry may be taken as indicative of another principle: that of placing marked senses after unmarked ones. This criterion (hailed as 
'distribution' by Fuertes-Olivera and Arribas-Baño 2008: 38) says that senses which are not in general use, are restricted geographically, pragmatically, or socially, should follow those not so restricted. Sound as it is, it is obvious that the policy is insufficient in itself, as most senses with serious claims for entry-initial placement will not be restricted in any way. It should be clear, then, that this principle will not be of much help in those decisions that determine the most salient form of the entry: those regarding the most salient meanings. It will, however, assist in deciding what to do with those senses which exhibit restriction in use.

\subsubsection{Frequency}

The idea behind frequency ordering is to present the sense in which the lemma is most frequently used as the first one, and then order the remaining senses in decreasing frequency. The criterion has been in use for some time, though in pre-corpus times frequency was evaluated subjectively by intuition, and an early publication on the topic, Kipfer (1984), writes of 'usage ordering'. But frequency-based ordering really came into its own with the introduction of electronic corpora. Even though corpus tools are still not quite capable of automatically counting the occurrences of words in specific senses, modern corpus query applications go a long way towards facilitating such estimates. There is no question that ordering by frequency is convenient for the lexicographer, providing a relatively objective ground for ordering decisions (issues of corpus balancing aside), but is it also in the best interest of the dictionary user? All too often authors claim that listing the most frequent senses at the top gives the user the best chance of finding what they want in the shortest time possible. The fact is, though, that such claims remain largely unproven. It was English monolingual dictionaries for advanced learners that embraced frequency ordering most enthusiastically. However, if we picture a scenario of advanced learners of English looking up the meaning of a common word (common words tend to have many senses, other things being equal), it is quite unlikely that they will be looking for the most frequent sense, as this sense will normally be quite familiar to advanced language learners. Indeed, I have heard comments from advanced learners of English that they start examining long entries from the bottom up, as they have discovered through extensive dictionary use that the senses they seek are often found towards the end of the entry. Perhaps it is the use of similar strategy that might account for the special salience of final senses noted by Nesi and Tan (2011).

Placing the most frequent sense first is rather more defensible if a dictionary is going to be used for text production (such as essay writing). Whereas looking up a frequent sense of a common word is not likely when the dictionary is being used for comprehension, users engaged in text production may wish to seek guidance or reassurance on the grammatical or collocational behaviour of a well-known sense. This invites the conclusion that the optimal sense ordering hangs on what the dictionary is actually used for (or is designed to be used for). In dynamic dictionaries of the future sense ordering might conceivably be adjusted depending on the circumstances of use (an idea developed in Lew 2009).

\subsubsection{Logic}

Logical ordering is sometimes invoked by dictionary editors in the front matter. The notion was subjected to close scrutiny by Hiorth (1954), and then Kipfer (1984), who found it to be merely a label with little content. Another term encountered in the front matter of dictionaries is psychologically-meaningful ordering (Kipfer 1984: 103), but it has never been made clear how these two types would actually differ. All in all, it seems that these different labels represent intuitive attempts at respecting the dictionary entry as a coherent text (cf. Frawley 1989), 
rather than seeing it as a loose amalgamation of independent senses. In order to present a more holistic picture of meaning, lexicographers should strive to present senses as related, to the extent that this is practical, typically by introducing an important core sense of some generality and then demonstrating how other peripheral senses relate to this pivotal sense. These senses may be derived from the core sense by meaning extension, specialization, or generalization, including the figurative processes of metaphor and metonymy (Van der Meer and Sansome 2001; Atkins and Rundell 2008; Wojciechowska 2012). We return to this issue below.

Unlike in applying the previous principles, this approach to sense ordering implies grouping senses at different levels of organizations, so the structure of the entry need not be flat. Instead, subsenses should be allowed to be nested under the main sense. A well-known exemplar of such an approach is the New Oxford Dictionary of English (Hanks and Pearsall 1998), where a systematic attempt has been made to cluster related subsenses under a smaller number of 'prototypical' senses. Its subsequent editions largely continue this tradition under the slightly changed title Oxford Dictionary of English.

The number of hierarchical levels can be larger than two, and the hierarchy can get quite elaborate. As Fraser (2008: 72) notes, large scholarly dictionaries may feature as many as four levels of sense organization, with a possible arrangement including the following:

overarching Divisions, labelled with capital letters (A, B, C); semantic Branches, with Roman numerals (I, II, II); Sections, with Arabic numerals (1, 2, 3); and Subsections, with lower-case letters $(\mathrm{a}, \mathrm{b}, \mathrm{c})$

A prominent exemplar of a dictionary with this style of sense organization (maximal, though not obligatory for every entry) is the Oxford English Dictionary.

\subsection{Ordering senses in bilingual dictionaries}

As we have already seen, entry structure in bilingual dictionaries may be carried over from a monolingual dictionary which may have been used as a starting point in the compilation of bilingual dictionaries. This routinely happens in the (often superficial) adaptations of monolingual dictionaries referred to as semi-bilingual or bilingualized dictionaries (Hartmann 1994). More interesting are those works in which senses in a bilingual entry have been organized around their equivalents. In such cases, there is an argument to be made for placing at the top those senses which include the most common textual equivalent in the TL, and give further senses in descending order of frequency of equivalents translating this headword (not the same, of course, as the absolute frequency of candidate equivalents). Another way to think of this measure is as conditional probability of a candidate equivalent appearing in a targetlanguage text, given the presence of the source lemma in a source-language text. The rationale for this ordering principle would be that a user seeking a TL equivalent, is first presented with equivalents which translate the headword in the largest proportion of cases. Until recently, such ordering would mostly be based on the intuition of the lexicographer. Currently, corpora are increasingly being used in the compilation of bilingual dictionaries, but they tend to be separate corpora for the two languages. As such, they can provide information on the frequent patterns of use of words, but offer no direct clues on the correspondences between the two lexical systems. However, advances in parallel corpora may soon allow meaningful assistance in the identification of the most common textual equivalents between languages. Even if the most frequent equivalents in texts are not in each and every case the best candidates for inclu- 
sion in all types of bilingual dictionaries, they are by and large the most serious candidates to consider.

\section{Helping dictionary users identify the relevant sense}

Polysemous entries present a special challenge to dictionary users, as they need to locate the relevant section of the entry. Research on dictionary use (Tono 1984; Bogaards 1998; Lew 2004) shows that users tend to look at the top part of the entry, and may not scan the whole entry unless there are obvious signals in the entry that the top sense is not what they should be looking at. There is also some evidence (Nesi and Tan 2011) that more sophisticated users tend to look at the final sense in the entry, but again, the material in the middle sections of the entry is not so easily accessible. To assist dictionary users in navigating long entries, two broad types of navigational aids have occasionally been used: (1) entry menus, and (2) sense guidewords (also known as signposts, shortcuts, or mini-definitions).

In both these types of navigational aids, the idea is to provide the user with rough-andready clues to the range of meaning or use covered within a specific sense section of the entry, and so direct them to the most relevant sense. The difference between the two types lies in their spatial organization, as illustrated below with a modified partial entry from the Seventh Edition of the Oxford Advanced Learners' Dictionary, as used in Lew's (2010) study.

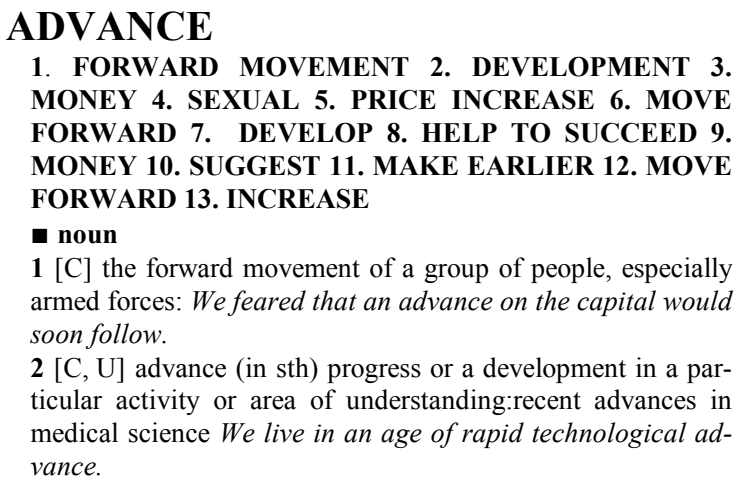

Entry menus gather all the clues in a solid block at the top of the entry (left-hand column above). In constrast, guidewords are distributed throughout the entry, with indicators introducing each sense (right-hand column above). The efficacy of such entry navigational aids has been established mainly in the context of monolingual dictionaries for language learners (Tono 1984; Tono 1992; Tono 1997; Bogaards 1998; Tono 2001; Lew and Pajkowska 2007). It would stand to reason that in bilingual dictionaries the need for such access-facilitating devices is diminished, as one of the languages of the dictionary would usually be the native language of the user, allowing for more efficient scanning of the entries than if the entries are all in a foreign language, as would be the case in a monolingual dictionary for language learners. However, recent research reveals that electronic bilingual dictionaries do benefit from clickable entry menus as long as the target sense is additionally highlighted (Lew and Tokarek 2010).

Direct comparisons between the two systems (Lew 2010; Nesi and Tan 2011) indicate that the distributed system works better. The advantage of guidewords over menus may be explained by the physical proximity between guidewords and full definitions, which allows the 
two entry elements to work in synergy. Also, since entry menus are found at the top of the entry, there is a real risk of dictionary users getting lost on the way from the menu to the sense down the entry, even if they have identified the relevant sense correctly in the menu itself, particularly if the entry is long and runs on to another page (on paper) or screen. This is much less of a risk when the clue is adjacent to its sense section of the entry, as it is in the guideword system.

\section{Defining senses}

Defining senses, or meanings, is most relevant to semasiological monolingual dictionaries. Most types of onomasiological dictionaries such as thesauri or synonym dictionaries tend not to have definitions, except perhaps for bringing out the differences between alternative lexical choices. Prototypical bilingual dictionaries do not normally employ definitions, working instead with equivalents in another language as the primary instrument for explaining meaning. Nevertheless, bilingual dictionaries sometimes do resort to definition in cases where an equivalent happens not to be available, or an equivalent would not be clear on its own. In such and similar cases, a definition (in this use often called a gloss) may be added for clarification.

\subsection{The form of definition}

For centuries, monolingual lexicography has been dominated by the Aristotelian model of defining. This format, also known as the classical definition, attempts to describe the defined item (definiendum) by supplying at least two pieces of information. First, it identifies the general category of things to which the defined belongs. Second, it specifies the features in which the thing defined distinguishes itself from other members of this broader category. The technical terms for the two elements of the classical definition are genus and differentia specifica (or, in the plural, differentiae specificae), respectively (though they need not necessarily come in this particular order). For example, if a HEATER is defined as 'a machine for making air or water hotter' (LDOCE online), then what the definition is telling us is that a heater is a type of machine (genus) with a particular function of making air or water hotter (differentia specifica). This defining strategy thus involves two complementary moves: a generalization followed by specialization.

Even though the classical definition has ruled for centuries, it has not ruled supreme. Studies by historical lexicographers (e.g. Osselton 2007; Stein 2011) have identified instances of other defining strategies, some of which have recently enjoyed a comeback.

Foremost amongst these has been the so-called full-sentence definition (FSD), brought to the contemporary limelight by the COBUILD range of dictionaries starting in 1987 (see Sinclair 1987). The case for FSD is made by Hanks (for more detail, see Hanks 1987). There are several variants of the full-sentence definition, but the most important characteristic is that the defined item is embedded in the definition itself, as in this definition from COBUILD online: 'A heater is a piece of equipment or a machine which is used to raise the temperature of something, especially of the air inside a room or a car.' Such full-sentence definitions are claimed to be more similar to regular discourse, and remind the reader of an explanation a teacher or parent might offer. However, studies into patterns of spontaneous defining (Fabiszewski-Jaworski 2011) do not confirm this claim: while the full-sentence format is used at times, the classical definition remains by far the most popular. Another feature of the FSD is that the inclusion of the definiendum in the definition creates an opportunity for highlighting typical word combinations with the item being defined. This is particularly common with verbs and adjectives, as in this COBUILD definition of INSTIL: 'If you instil an idea or feeling in someone, especially over a period of time, you make them think it or feel it.' 
Other dictionaries have not adopted the full-sentence definition to the extent that the COBUILD range has. Amongst the problems of this defining format are: excessive wordiness, complexity, and appeal to conventions that remain largely obscure to the average user (Rundell 2006). Still, the FSD is used in moderation in most current monolingual English dictionaries for learners, and the format has inspired a lot of lexicographic research, some of which continues to this day (Barnbrook 2012).

A related defining format is the single-clause definition, used most readily to define abstract nouns, especially ones which lack a useful genus term. Instead of defining DESTRUCTION as 'the act or process of destroying something or of being destroyed' (LDOCE online), the single-clase alternative would just say 'when something is being destroyed', avoiding the clumsy and over-general act or process. It may well be that such general words do not contribute that much to the explanation of the exact meaning of the definiendum, but at least they do indicate that a noun is being defined: something that the single-clause definition does a poor job at (Dziemianko and Lew 2006; Lew and Dziemianko 2006b; Lew and Dziemianko 2006a; Lew and Dziemianko 2012).

A frequent defining strategy in concise dictionaries is to give a synonym or several synonyms. Interestingly, such a defining strategy bears affinity to the methods of bilingual lexicography: a synonym can be thought of as a special type of (near-)equivalent. While a bilingual dictionary provides equivalents in another language, synonym definitions may represent a different regional variety (e.g. KIRK $S \cot E$ church) or register (PUKE infml vomit). Whenever a lemma represents a non-neutral item, as in the last case, and is rendered with a synonym in general use, the use of a synonym as a definition is generally accepted. Otherwise, it is frowned upon as a lexicographer's easy way out.

A number of other defining formats are occassionally used, such as the morphological definition (a formulation unwrapping a derivative word, e.g. SWIFTLY in a swift fashion), extensional definition (enumerating typical exemplars, e.g. LEGUME a seed such as a pea or bean), or ostensive definition (pointing to the definiendum, e.g. BLACK the colour of this print).

The above classification of definition formats has mostly dealt with the syntactic devices by means of which definitional sequences are put together. But the ultimate building blocks of definitions are words, and there is a general, and not altogether unreasonable, expectation that those words be simpler than the word being defined. Of course, this is hardly possible in defining the most common vocabulary (whose presence in monolingual dictionaries is somewhat tokenistic). The requirement of defining in simple words found a systematic and formal implementation in the so-called vocabulary control movement of the mid- $20^{\text {th }}$ century (Cowie 1999), out of which grew the defining vocabularies of the major monolingual English learners' dictionaries. These vocabulary lists typically consist of between 2,000 and 3,500 words in their most common senses, and it is with the use of this restricted set that the definitions of up to 100,000 senses recorded in such dictionaries are written. It is often argued that the use of restricted vocabulary generally makes definitions easier to understand. While this is probably so, it is also true that the formulations become less precise, more wordy and roundabout, if not downright strained. The artificiality extends to the unnatural collocational patterns, as the natural collocates may not be in the defining vocabulary set. Problems such as these throw into question the rigid restrictions imposed by defining vocabulary lists. As an alternative, Hanks (2009: 307) proposes that while definitions should be 'as simple as possible', they should at the same time be 'as complex as necessary'. This appears to be a reasonable position, given the numerous problems associated with the use of restricted defining vocabulary. 
Rather than trying to dumb down definitions for language learners, publishers should offer bilingual learners' dictionaries (Adamska-Sałaciak 2010).

\subsection{Relations between definitions of different senses}

Lexicographers defining polysemous entries need to grapple with the issue of relatedness between different senses. On the one hand, foregrounding the links between different shades of meaning may help repair some of the damage done by artificially chopping semantic space into separate dictionary senses. In line with this consideration, there are those who stress that the dictionary entry is just one type of text (e.g. Frawley 1989), with its own cohesive links. Arguably, readers going through the entry can benefit from the definitions of subsequent senses building on the preceding ones, at the same time avoiding repetition.

As a result, however, some definitions may become impossible to interpret without the contextual support of the earlier ones ('an instance of this' is a classic formulation in lexicographese, its popularity probably due more to space-saving considerations than to anything else). The assumption underlying such defining practice is that dictionary users behave as entry readers. This assumption can be problematic, as dictionary users do not have to, and often do not care to, go through the complete entry, if they are looking for a quick solution. On such a scenario, it may be more advantageous if a definition of each sense is relatively autonomous, so that its comprehension does not send the dictionary user on a quest for clues all over the entry.

One way to approach the issue of how closely the senses should be interrelated is through the primary function of the dictionary. Using a dictionary for comprehension favours quick consultation, and for such uses, relatively autonomous senses might work best. In contrast, if an entry is used for browsing or vocabulary learning, the user is likely to spend more time examining larger portions of the entry, and for such uses a more holistic approach to defining may be more suitable.

\section{References}

Adamska-Sałaciak, A. (2010), 'Why we need bilingual learners' dictionaries', in I.J. Kernerman and P. Bogaards (eds.), English learners' dictionaries at the DSNA 2009. Tel Aviv: K Dictionaries, pp. 121-37.

Atkins, B.T.S. (1996), 'Bilingual dictionaries - past, present and future', in M. Gellerstam, J. Jarborg, S.-G. Malmgren, K. Noren, L. Rogström and C.R. Papmehl (eds.), EURALEX '96 Proceedings. Göteborg: Department of Swedish, Göteborg University, pp. 515-46.

Atkins, B.T.S. and Rundell, M. (2008), The Oxford Guide to Practical Lexicography. Oxford: Oxford University Press.

Barnbrook, G. (2012), 'A sense of belonging: possessives in dictionary definitions', International Journal of Lexicography.

Bogaards, P. (1998), 'Scanning long entries in learner's dictionaries', in T. Fontenelle, P. Hiligsmann, A. Michiels, A. Moulin and S. Theissen (eds.), EURALEX '98 Actes/Proceedings. Liege: Université Départements d'Anglais et de Néerlandais, pp. 555-63.

Burkhanov, I. (1997), 'On the correlation between lexicology, linguistic semantics and lexicography', Zeszyty Naukowe Wyższej Szkoły Pedagogicznej w Rzeszowie. Seria Filologiczna. Językoznawstwo 4, (26). 55-73. 
Cowie, A.P. (1999), English dictionaries for foreign learners: A history. Oxford: Clarendon Press.

Dziemianko, A. and Lew, R. (2006), 'When you are explaining the meaning of a word: The effect of abstract noun definition format on syntactic class identification', in E. Corino, C. Marello and C. Onesti (eds.), Atti del XII Congresso di Lessicografia, Torino, 6-9 settembre 2006. Allessandria: Edizioni dell'Orso, pp. 857-63.

Fabiszewski-Jaworski, M. (2011), 'Spontaneous defining by native speakers of English', in K. Akasu and S. Uchida (eds.), ASIALEX2011 Proceedings Lexicography: Theoretical and practical perspectives. Kyoto: Asian Association for Lexicography, pp. 102-09.

Fraser, B.L. (2008), 'Beyond Definition: Organising Semantic Information in Bilingual Dictionaries', International Journal of Lexicography 21, (1). 69-93.

Frawley, W. (1989), 'The Dictionary as Text', International Journal of Lexicography 2, (3). 231-48.

Fuertes-Olivera, P.A. and Arribas-Baño, A. (2008), Pedagogical specialised lexicography: The representation of meaning in English and Spanish business dictionaries. Terminology and Lexicography Research and Practice 11. Amsterdam: John Benjamins.

Hanks, P. (1987), 'Definitions and explanations', in J. Sinclair (ed.), Looking up: An account of the COBUILD project in lexical computing. London - Glasgow: Collins, pp. 116-36.

Hanks, P. (2000), 'Do word meanings exist?', Computers and the Humanities 34, (1-2). $205-$ 15.

Hanks, P. (2009), 'Review of Stephen J. Perrault (ed.). 2008. Merriam-Webster's Advanced Learner's English Dictionary', International Journal of Lexicography 22, (3). 301-15.

Hanks, P. and Pearsall, J. (eds.). (1998), New Oxford Dictionary of English. Oxford: Oxford University Press.

Hartmann, R.R.K. (1985), 'Contrastive Text Analysis and the Search for Equivalence in the Bilingual Dictionary', in K. Hyldegaard-Jensen and A. Zettersten (eds.), Symposium on Lexicography II. Proceedings of the Second International Symposium on Lexicography, May 1984, at the University of Copenhagen, (Lexicographica Series Maior 5). Tübingen: Niemeyer, pp. 121-32.

Hartmann, R.R.K. (1994), 'Bilingualised versions of learners' dictionaries', Fremdsprachen Lehren und Lernen 23. 206-20.

Hiorth, F. (1954), 'Arrangement of meanings in lexicography : Purpose, disposition and general remarks', Lingua 4. 413-24.

Jarošová, A. (2000), 'Problems of semantic subdivisions in bilingual dictionary entries', International Journal of Lexicography 13, (1). 12-28.

Kilgarriff, A. (1997), 'I don't believe in word senses', Computers and the Humanities 31, (2). 91-113.

Kipfer, B.A. (1984), Workbook on lexicography: A course for dictionary users. Exeter: University of Exeter.

Lew, R. (2004), Which dictionary for whom? Receptive use of bilingual, monolingual and semi-bilingual dictionaries by Polish learners of English. Poznań: Motivex.

Lew, R. (2009), 'Towards variable function-dependent sense ordering in future dictionaries', in H. Bergenholtz, S. Nielsen and S. Tarp (eds.), Lexicography at a crossroads: Dictionaries and encyclopedias today, lexicographical tools tomorrow, (Linguistic insights - studies in language and communication, Vol.90). Bern: Peter Lang, pp. 23764. 
Lew, R. (2010), 'Users take shortcuts: Navigating dictionary entries', in A. Dykstra and T. Schoonheim (eds.), Proceedings of the XIV Euralex International Congress. Ljouwert: Afûk, pp. 1121-32.

Lew, R. and Dziemianko, A. (2006a), 'A new type of folk-inspired definition in English monolingual learners' dictionaries and its usefulness for conveying syntactic information', International Journal of Lexicography 19, (3). 225-42.

Lew, R. and Dziemianko, A. (2006b), 'Non-standard dictionary definitions: What they cannot tell native speakers of Polish', Cadernos de Traduçao 18. 275-94.

Lew, R. and Dziemianko, A. (2012), 'Single-clause when-definitions: take three', Proceedings of 15th EURALEX International Congress, Oslo, 7-11 August, 2012. Oslo: Oslo University.

Lew, R. and Pajkowska, J. (2007), 'The effect of signposts on access speed and lookup task success in long and short entries', Horizontes de Lingüistica Aplicada 6, (2). 235-52.

Lew, R. and Tokarek, P. (2010), 'Entry menus in bilingual electronic dictionaries', in S. Granger and M. Paquot (eds.), eLexicography in the 21st century: New challenges, new applications. Louvain-la-Neuve: Cahiers du CENTAL, pp. 193-202.

Manley, J., Jacobsen, J.R. and Pedersen, V.H. (1988), 'Telling lies efficiently: Terminology and the microstructure in the bilingual dictionary', in K. Hyldgaard-Jensen and A. Zettersten (eds.), Symposium on lexicography III. Tübingen: Max Niemeyer, pp. 281301.

McCreary, D.R. (2008), 'Looking Up "Hard Words" for a Production Test: A Comparative Study of the NOAD, MEDAL, AHD, and MW Collegiate Dictionaries', in E. Bernal and J. DeCesaris (eds.), Proceedings of the XIII EURALEX International Congress. Barcelona: Universitat Pompeu Fabra, pp. 1287-93.

McCreary, D.R. (2010), 'Three collegiate dictionaries: A comparison of reading comprehension test scores for university students using MWCD11, AHD4, and NOAD2', in I. Kernerman and P. Bogaards (eds.), English Learners' Dictionaries at the DSNA 2009. Tel Aviv: K Dictionaries, pp. 55-74.

McCreary, D.R. and Amacker, E. (2006), 'Experimental research on college students' usage of two dictionaries: A comparison of the Merriam-Webster Collegiate Dictionary and the Macmillan English Dictionary for Advanced Learners', in E. Corino, C. Marello and C. Onesti (eds.), Atti del XII Congresso di Lessicografia, Torino, 6-9 settembre 2006. Allessandria: Edizioni dell'Orso, pp. 871-85.

Mish, F.C. (2004), 'Merriam-Webster's Collegiate Dictionary, Eleventh Edition'. Springfield, Massachusetts: Merriam-Webster Incorporated.

Nesi, H. and Tan, K.H. (2011), 'The effect of menus and signposting on the speed and accuracy of sense selection', International Journal of Lexicography 24, (1). 79-96.

Nowakowski, M. (1990), 'Metaphysics of the dictionary versus the lexicon', in J. Tomaszczyk and B. Lewandowska-Tomaszczyk (eds.), Meaning and lexicography. Amsterdam: John Benjamins Publishing Company, pp. 5-19.

Osselton, N.E. (2007), 'Innovation and Continuity in English Learners' Dictionaries: The Single-clause When-definition', International Journal of Lexicography 20, (4). 39399.

Piotrowski, T. (1994), Problems in bilingual lexicography. Wrocław: Wydawnictwo Uniwersytetu Wrocławskiego.

Rundell, M. (1999), 'Dictionary use in production', International Journal of Lexicography 12, (1). 35-53.

Rundell, M. (2006), 'More than one way to skin a cat: Why full-sentence definitions have not been universally adopted', in E. Corino, C. Marello and C. Onesti (eds.), Atti del XII 
Congresso di Lessicografia, Torino, 6-9 settembre 2006. Allessandria: Edizioni dell'Orso, pp. 323-37.

Shcherba, L.V. (1995), 'Towards a general theory of lexicography', International Journal of Lexicography 8, (4). 314-50.

Sinclair, J. (ed.), (1987), Looking up: An account of the COBUILD project in lexical computing. London - Glasgow: Collins.

Sinclair, J. and Hanks, P. (1987), 'Collins COBUILD English Language Dictionary'. COBUILD1. London - Glasgow: Collins.

Stein, G. (2011), 'The linking of lemma to gloss in Elyot's Dictionary (1538)', in O. Timofeeva and T. Säily (eds.), Words in dictionaries and history. Essays in honour of R.W. McConchie. Amsterdam: John Benjamins Publishing Company, pp. 55-79.

Tono, Y. (1984), On the dictionary user's reference skills. B.Ed. Thesis, Tokyo Gakugei University.

Tono, Y. (1992), 'The effect of menus on EFL learners' look-up processes', Lexikos 2. 230-53.

Tono, Y. (1997), 'Guide Word or Signpost? An experimental study on the effect of meaning access indexes in EFL learners' dictionaries', English Studies 28. 55-77.

Tono, Y. (2001), Research on dictionary use in the context of foreign language learning: Focus on reading comprehension. Lexicographica Series Maior 106. Tübingen: Niemeyer.

Van der Meer, G. (2004), 'On defining: Polysemy, core meanings, and "great simplicity", in G. Williams and S. Vessier (eds.), Proceedings of the Eleventh EURALEX International Congress, EURALEX 2004, Lorient, France, July 6-10, 2004, Vol.2. Lorient: Université De Bretagne Sud, pp. 807-15.

Van der Meer, G. and Sansome, R. (2001), 'OALD6 in a Linguistic and a Language Teaching Perspective', International Journal of Lexicography 14, (4). 283-306.

Wojciechowska, S. (2012), Conceptual metonymy and lexicographic representation. Frankfurt: Peter Lang. 